\title{
Estimasi Karakteristik Reservoir Panas Bumi dari Sumber Mata Air Panas di Kecamatan Pauh Duo, Kabupaten Solok Selatan
}

\author{
Randa Permanda*, Ardian Putra \\ Laboratorium Fisika Bumi, Jurusan Fisika FMIPA Universitas Andalas \\ Kampus UNAND Limau Manih, Padang, 25163 \\ *randapermanda27@gmail.com,ardhee@fmipa.unand.ac.id
}

\begin{abstract}
ABSTRAK
Dalam kegiatan eksplorasi pendahuluan dan proses pengembangan lapangan panas bumi, kandungan fluida panas bumi sangat berguna untuk memberikan perkiraan mengenai karakteristik reservoir panas bumi. Kandungan fluida panas bumi dapat memberikan gambaran mengenai temperatur dan jenis reservoir serta tipe fluida panas bumi. Konsentrasi dari unsur-unsur fluida panas bumi dapat dimanfaatkan untuk memperkirakan temperatur resevoir panas bumi dengan menggunakan persamaan geotermometer. Penelitian ini akan mengestimasi karakteristik reservoir panas bumi berdasarkan lima sumber mata air panas di Kecamatan Pauh Duo, Kabupaten Solok Selatan. Tipe fluida dan karakteristik reservoir panas buminya dipelajari melalui pengukuran $\mathrm{pH}$, temperatur permukaan, dan uji kandungan mata air panas dengan menggunakan Atomic Absorption Spectrophotometer (AAS) dan spektrofotometer visible. Konsentrasi unsur yang diteliti yaitu $\mathrm{Na}, \mathrm{K}, \mathrm{Ca}$, dan $\mathrm{SiO}_{2}$ dan didapatkan konsentrasi unsur dari urutan yang terbesar adalah $\mathrm{Ca}, \mathrm{Na}, \mathrm{K}$, dan $\mathrm{SiO}_{2}$. Kandungan unsur ini dimasukkan ke dalam beberapa persamaan geotermometer, seperti persamaan geotermometer silika dan Na-K-Ca. Persamaan geotermometer yang cocok pada daerah penelitian adalah persamaan geotermometer Na-K-Ca dan silika amorf dengan nilai estimasi temperatur reservoir $224^{\circ} \mathrm{C}-332^{\circ} \mathrm{C}$. Nilai estimasi temperatur reservoir mengindikasikan bahwa kelima sumber mata air panas berasal dari sistem reservoir yang sama. Nilai estimasi ini berada dalam kisaran nilai estimasi temperatur reservoir yang diperoleh oleh PT. Supreme Energy yaitu $210^{\circ} \mathrm{C}-320^{\circ} \mathrm{C}$. Mata air panas di daerah penelitian memiliki pH netral $(6,8-7,4)$. Berdasarkan nilai ini, tipe fluida mata air panas di Kecamatan Pauh Duo, Kabupaten Solok Selatan adalah alkali klorida dan sistem panas buminya didominasi oleh air.
\end{abstract}

\begin{abstract}
Geothermal fluid is important tool to observe the characteristics of geothermal reservoirs in the preliminary study and development of geothermal field. The chemical composition of fluid can provide information on temperature and system reservoir as well as types of geothermal fluid. The chemical composition of the hot spring can be used to estimate the temperature reservoir using the geothermometry equation. This research will estimate the characteristics of reservoir geothermal energy for 5 hot springs in Pauh Duo District, South Solok Regency. Type of fluids and the reservoir characteristic will be analyzed by using the value of $\mathrm{pH}$, surface temperature, and chemical composition measured by Atomic Absorption Spectrophotometer (AAS) and spectrophotometer visible. Several chemical compositions of the fluid $\mathrm{Na}, \mathrm{K}, \mathrm{Ca}$, and $\mathrm{SiO}_{2}$ were investigated and it was found that $\mathrm{Ca}$ is the chemical composition with the highest concentration in all samples, followed by $\mathrm{Na}$, $\mathrm{K}$, and $\mathrm{SiO}_{2}$. These composition were applied to silica and $\mathrm{Na}-\mathrm{K}$-Ca.geothermometry equation. The best equation to estimate the temperature of reservoir in the sampling area are geothermometry amorphous silica and $\mathrm{Na}-\mathrm{K}-\mathrm{Ca}$ that provide similar temperature $\left(224-332^{\circ} \mathrm{C}\right)$. The five hot springs in the sampling area are come from same reservoir in which all the temperature lie in the temperature obtained by PT. Supreme Energy $\left(210^{\circ} \mathrm{C}-320^{\circ} \mathrm{C}\right)$. Furthermore, the value of $\mathrm{pH}$ showed that all samples are in neutral condition $(6,8-7,4)$ with fluid type being alkali chloride and reservoir dominated by water.
\end{abstract}

\section{PENDAHULUAN}

Solok Selatan merupakan salah satu daerah yang memiliki potensi panas bumi di Sumatra Barat. Solok Selatan berada pada segmen Suliti yang melintang sepanjang $95 \mathrm{~km}$ dari Gunung Talang sampai Gunung Kerinci. Segmen Suliti merupakan bagian dari segmen Sesar Sumatra. Pola struktur geologi tersebut mengontrol terjadinya sistem panas bumi di Solok Selatan, yang berhubungan dengan kehadiran manifestasi permukaan. Potensi panas bumi di Solok Selatan diperkirakan mencapai 220 MW, dimana sanggup untuk menopang pembangkit listrik sebesar 30 tahun ke depan (Wisnandary dan Alamsyah, 2012).

Ada beberapa tahapan eksplorasi dan pengembangan lapangan panas bumi, salah satunya adalah eksplorasi pendahuluan. Eksplorasi pendahuluan dilakukan untuk mencari 
daerah prospek panas bumi yang menunjukkan tanda-tanda adanya sumber daya panas bumi dilihat dari kenampakannya di permukaan. Pada tahap awal eksplorasi pendahuluan ini dilakukan studi literatur, survei lapangan, dan analisis data. Pada survei lapangan akan diambil sampel berupa jenis-jenis manifestasi permukaan panas bumi daerah tersebut, salah satunya adalah fluida (Saptadji, 2009).

Daerah Kecamatan Pauh Duo, Solok Selatan memiliki potensi sumber daya energi panas bumi. Hal ini ditandai dengan ditemukannya manifestasi permukaan berupa mata air panas dan endapan sinter silika sekitar mata air panas. Untuk melihat potensi tersebut, maka pada daerah Kecamatan Pauh Duo ini dilakukan estimasi karakteristik reservoir panas bumi yang meliputi tipe fluida panas bumi, temperatur reservoir dan sistem reservoir dari manifestasi permukaan yang ada. Daerah penelitian ini berada dalam kawasan Muara Laboh. Wisnandary dan Alamsyah (2012) dari PT. Supreme Energy pernah melakukan pemodelan numerik di daerah Muaro Laboh menggunakan data geologi, geofisika, dan geokimia (3G). Data geoscientific menunjukkan daerah Muaro Laboh diperkirakan memiliki temperatur reservoir panas bumi dengan kisaran nilai $210-320^{\circ} \mathrm{C}$ dengan sistem reservoir didominasi air. Hasil estimasi dari penelitian ini dibandingkan dengan hasil yang diperoleh oleh PT. Supreme Energy sebagai acuan referensi.

\section{METODE}

\subsection{Lokasi Penelitian dan Sampel}

Lokasi penelitian berada di Kecamatan Pauh Duo, meliputi 5 titik sumber mata air panas yang tersebar di 3 titik daerah Sapan Maluluang, 1 titik di daerah Saringan, dan 1 titik di daerah Pakan Salasa, sebagaimana dapat dilihat pada Gambar 1. Manifestasi permukaan di 5 titik sampel penelitian berbeda-beda, ada berupa mata air panas (hot springs), kolam air panas, telaga air panas, dan endapan sinter silika. Pada sampel mata air ke-1 manifestasi berupa mata air panas dan endapan sinter silika di sekitar mata air. Hanya pada mata air ke-1 yang ditemukan endapan sinter silika. Pada mata air panas ke-2 dan ke-3, manifestasi berupa hot springs tanpa adanya endapan sinter silika. Lokasi mata air panas ke-1, 2, dan 3 letaknya sangat berdekatan, berada di daerah Sapan Maluluang. Daerah penelitian ke-4 berada di Saringan dengan manifestasi permukaan berupa telaga (Gambar 2.b). Untuk mata air panas ke-5 berada di daerah Pakan Salasa yang telah dialokasikan sebagai kolam pemandian air panas. Manifestasi permukaan daerah penelitian dapat dilihat pada Gambar 2.

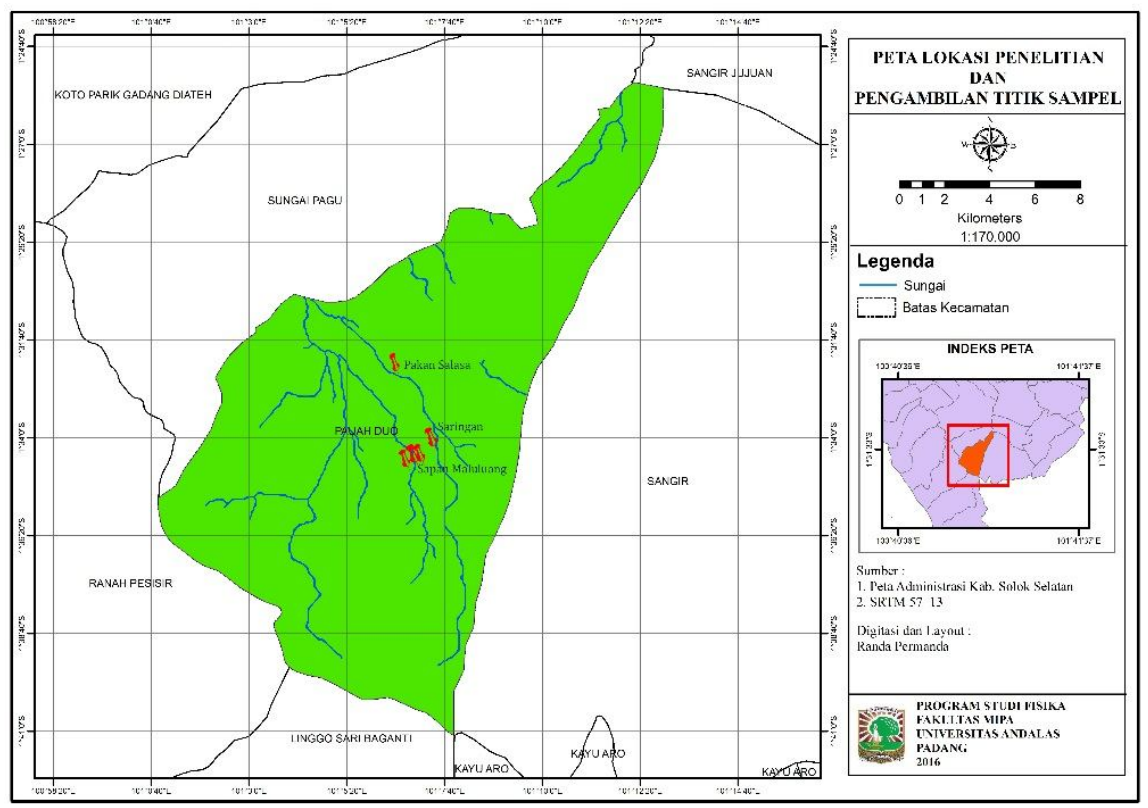

Gambar 1. Daerah penelitian dan titik pengambilan sampel ditandai dengan titik berwarna merah 


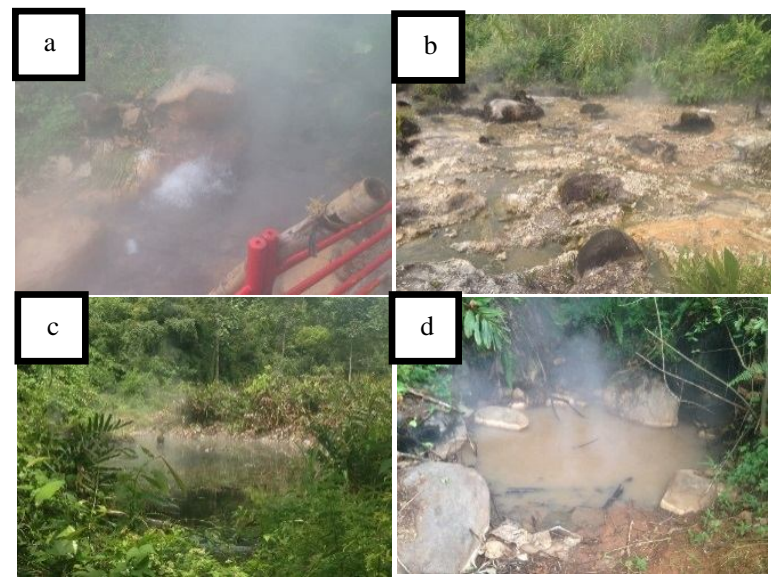

Gambar 2. Manifestasi Permukaan Daerah Penelitian, (a) Mata air panas ke-1 di Sapan Maluluang (b) Sinter silika di sekitar mata air panas ke-1 (c) Telaga air panas di Saringan (d) Mata Air Panas ke-3 di Sapan Maluluang

\subsection{Uji Kandungan Mineral}

Kandungan mineral yang terdapat pada lima sumber mata air panas yang diuji adalah $\mathrm{Na}, \mathrm{K}, \mathrm{Ca}$, dan $\mathrm{SiO}_{2}$ dilakukan dengan menggunakan alat Atomic Absorption Spectroscopy (AAS) dan spektrofotometer visible. Setelah mengetahui konsentrasi masing-masing kandungan logam $\mathrm{Na}, \mathrm{K}, \mathrm{Ca}$, dan $\mathrm{SiO}_{2}$, masing-masing konsentrasi tersebut dimasukkan ke dalam beberapa persamaan geotermometer. Dan selanjutnya dilakukan analisa persamaan geotermometer yang cocok dengan daerah penelitian.

\subsection{Pengukuran pH, Temperatur Permukaan, Konduktivitas Air, dan Resisitivitas Listrik Sinter Silika}

Temperatur permukaan sampel diukur menggunakan termometer analog. Pengukuran ini dilakukan langsung pada masing-masing sampel di lokasi objek penelitian. Untuk konduktivitas air diukur menggunakan conductivity meter, sedangkan pengukuran $\mathrm{pH}$ menggunakan $\mathrm{pH}$ meter. Hal ini perlu dilakukan untuk menganalis karakteristik jenis reservoir panas bumi daerah penelitian.

Sifat air dan kandungan kimia air dapat digunakan sebagai sebagai dasar perkiraan awal tentang jenis reservoir. Mata air panas yang bersifat netral $(\mathrm{pH} \mathrm{6-7,5)} \mathrm{biasanya} \mathrm{merupakan}$ manifestasi permukaan dari suatu sistem panas bumi dominasi air. Mata air panas yang bersifat netral umumnya kandungan $\mathrm{Cl}$ relatif tinggi dan jenuh dengan silika $\left(\mathrm{SiO}_{2}\right)$. Apabila laju aliran air panas tidak terlalu besar umumnya di sekitar mata air panas tersebut terbentuk teras-teras silika yang berwarna keperakan (Saptadji, 2009).

Ada beberapa jenis air panas bumi, yaitu air alkali klorida, air asam sulfat, air asam sulfat klorida, dan air bikarbonat. Air alkali klorida memiliki ciri-ciri yaitu kandungan $\mathrm{Cl}$ yang tinggi (400-1800 ppm), kandungan $\mathrm{Na}$ dan $\mathrm{K}$ yang tinggi, kandungan $\mathrm{Ca}$ rendah, dan $\mathrm{SiO}_{2}$ cukup tinggi, memiliki $\mathrm{pH}$ sekitar 6-7,5. Air asam sulfat biasanya terkandung di daerah vulkanik dengan kandungan $\mathrm{SO}_{4}{ }^{-}$tinggi, mengandung $\mathrm{Na}, \mathrm{K}, \mathrm{Ca}, \mathrm{Mg}$, dan $\mathrm{Fe}$, serta memiliki $\mathrm{pH}$ yang rendah $(<2-3)$. Air asam sulfat-klorida biasanya terjadi karena pencampuran alkali klorida dan asam sulfat. Hal ini disebabkan karena air alkali klorida melewati dan bereaksi dengan batuan yang mengandung sulfur. Kandungan $\mathrm{Cl}^{-}$dan $\mathrm{SO}^{-}$cukup tinggi, dan memiliki ph $<2-5$. Air karbonat disebabkan oleh adanya batuan limestone di bawah permukaan. Hal ini dicirikan oleh adanya endapan tranvertin $\left(\mathrm{CaCO}_{3}\right)$ di sekitar mata air panas. Air ini biasanya memiliki kandungan $\mathrm{HCO}_{3}^{-}$yang tinggi, $\mathrm{Cl}^{-}$rendah, dan $\mathrm{pH}$ sekitar 5-6.

Selain itu, pada mata air ke-1 dilakukan penghitungan nilai resistivitas listrik sinter silika untuk melihat karakteristik hambatan jenis dari sinter silika menggunakan metode probe dua elektroda. Pengujian resistivitas listrik sinter silika ini dilakukan dengan mengalirkan listrik pada bahan yang selanjutnya dilakukan berbagai macam variasi tegangan $(V)$ untuk 
mendapatkan nilai arus. Setelah itu dilakukan perhitungan nilai resistansi dan resistivitasnya dengan rumus sebagai berikut:

$$
\begin{aligned}
& V=I R \\
& R=\frac{\rho l}{A}
\end{aligned}
$$

\subsection{Estimasi Temperatur}

Data fluida panas bumi sangat berguna untuk memberikan perkiraan mengenai sistem panas bumi yang terdapat di bawah permukaan, seperti temperatur dan jenis reservoir. Salah satu metode yang digunakan untuk memperkirakan temperatur reservoir dari data fluida adalah geotermometer. Geotermometer adalah suatu persamaan yang menggunakan konsentrasi dari unsur-unsur kimia fluida panas bumi untuk memperkirakan temperatur reservoir atau temperatur sumber air di bawah permukaan (Saptadji, 2009). Beberapa jenis-jenis geotermometer:

a. Geotermometer Na-K-Ca

Asumsi-asumsi yang digunakan untuk membuat persamaan geotermometer $\mathrm{Na}-\mathrm{K}-\mathrm{Ca}$ adalah biasanya terdapat kandungan silika, dan aluminium tetap berada pada fasa padat (miskin $\mathrm{Al})$. Rumus persamaan dari geotermometer $\mathrm{Na}-\mathrm{K}-\mathrm{Ca}$ adalah:

$$
T=\frac{1647}{\log \left(\frac{[N a]}{[K]}\right)+\left(\beta \log \left(\frac{\sqrt{[C a]}}{[N a]}\right)+2,06\right)+2,47}-273,15
$$

Jika nilai $[\log \sqrt{ } \mathrm{Ca} / \mathrm{Na})+2.06]<0$, maka digunakan $\beta=1 / 3$ dan jika nilai $[\log \sqrt{ } \mathrm{Ca} / \mathrm{Na})+2.06]>$ 0 , gunakan $\beta=4 / 3$. Apabila pada $\beta=4 / 3$, nilai $T$ didapatkan $<100^{\circ} \mathrm{C}$ maka hasil dapat diterima. Tetapi apabila hasil perhitungan $T>100^{\circ} \mathrm{C}$, hitung ulang nilai $T$ dengan $\beta=1 / 3$.

b. Geotermometer Silika $\left(\mathrm{SiO}_{2}\right)$

Berbagai jenis persamaan geotermometer silika ditampilkan pada Tabel 1 (hasil simulasi beberapa peneliti), di mana penerapannya sangat tergantung kepada kondisi fluida dan jenis endapan silika yang dijumpai (keterangan : $\mathrm{C}=$ konsentrasi $\mathrm{SiO}_{2}$ pada fluida dalam ppm). Persamaan-persamaan pada Tabel 1 dikembangkan berdasarkan pendekatan terhadap nilai kurva kelarutan macam-macam mineral silika (kuarsa, kalsedon, kristobalit, opal, dan silika amorf).

Tabel 1. Persamaan geotermometer silika (Sumber: Aribowo, 2011)

\begin{tabular}{|l|l|l|}
\hline \multicolumn{1}{|c|}{ Geothermometer } & \multicolumn{1}{|c|}{ Persamaan } & \multicolumn{1}{c|}{ Referensi } \\
\hline $\begin{array}{l}\text { Quartz-no steam loss } \\
\text { Quartz-maximum steam } 100{ }^{\circ} \mathrm{C}\end{array}$ & $\mathrm{T}=1309 /(5.19-\log \mathrm{C})-273.15$ & Fournier (1977) \\
\hline Quartz & $\mathrm{T}=1522 /(5.75-\log \mathrm{C})-273.15$ & Fournier (1977) \\
\hline Quartz & $\begin{array}{l}\mathrm{T}=42.198+0.28831 \mathrm{C}-3.6686 \times 10^{-4} \mathrm{C}^{2}+3.1665 \times \\
10^{-7} \mathrm{C}^{3}+77.034 \log \mathrm{C}\end{array}$ & $\begin{array}{l}\text { Fournier and Potter } \\
(1982)\end{array}$ \\
\hline Chalcedony & $\begin{array}{l}\mathrm{T}=53.500+0.11236 \mathrm{C}-0.5559 \times 10^{-4} \mathrm{C}^{2}+0.1772 \times \\
10^{-7} \mathrm{C}^{3}+88.390 \log \mathrm{C}\end{array}$ & Arnorsson (1985) \\
\hline Chalcedony & $\mathrm{T}=1032 /(4.69-\log \mathrm{C})-273.15$ & Fournier (1977) \\
\hline Cristobalite & $\mathrm{T}=1112 /(4.91-\log \mathrm{C})-273.15$ & Arnorsson (1983) \\
\hline Opal & $\mathrm{T}=1000 /(4.78-\log \mathrm{C})-273.15$ & Fournier (1977) \\
\hline Amorphous silica & $\mathrm{T}=731 /(4.52-\log \mathrm{C})-273.15$ & Fournier (1977) \\
\hline
\end{tabular}




\section{HASIL DAN DISKUSI}

\subsection{Data Pengujian}

Konsentrasi kandungan $\mathrm{Na}, \mathrm{K}, \mathrm{Ca}$, dan $\mathrm{SiO}_{2}$ pada 5 sampel uji sangat tinggi (>1000 ppm). Kandungan rata-rata paling tinggi teramati pada sampel mata air ke-3, pada masingmasing sampel, kandungan konsentrasi mineral terbesar adalah Kalsium (Ca). Selain itu, semua sampel mata air panas kaya akan kandungan mineral $\mathrm{Na}, \mathrm{K}$ dan $\mathrm{SiO}_{2}$ (Tabel 3).

Tabel 3. Data Kandungan Unsur Sampel

\begin{tabular}{lllllll}
\hline \multirow{2}{*}{ Parameter } & \multirow{2}{*}{ Satuan } & \multicolumn{7}{c}{ Sampel } \\
\cline { 3 - 7 } & & $\mathbf{1}$ & $\mathbf{2}$ & $\mathbf{3}$ & $\mathbf{4}$ & $\mathbf{5}$ \\
\hline Kalsium $(\mathrm{Ca})$ & ppm & 5607 & 6000 & 8107 & 6071 & 6643 \\
Kalium $(\mathrm{K})$ & ppm & 1979 & 2149 & 2939 & 2227 & 2106 \\
Natrium $(\mathrm{Na})$ & ppm & 2618 & 2824 & 3794 & 2265 & 2471 \\
Silikat $\left(\mathrm{SiO}_{2}\right)$ & ppm & 1469 & 1673 & 2051 & 1337 & 1541 \\
\hline
\end{tabular}

\subsection{Karakteristik, pH dan Temperatur Permukaan Mata Air Panas}

Data pengukuran $\mathrm{pH}$ dan temperatur permukaan pada masing-masing sampel dirangkum pada Tabel 4. Data temperatur permukaan 5 mata air panas mempunyai rentang nilai $43^{\circ}-91^{\circ} \mathrm{C}$. Pada sampel mata air panas $1,2,3$ nilai temperatur yang didapatkan hampir sama. Hal ini dikarenakan letak mata air panas 1, 2, 3 yang berdekatan. Pada mata air ke-4, manifestasi berupa telaga, sehingga kesulitan untuk mengukur temperatur permukaan pusat yang berada di tengah telaga. Akses untuk mengukur temperatur hanya bisa di tepi (pinggir) telaga. Temperatur di tepi telaga mencapai $49^{\circ} \mathrm{C}$, diprediksi temperatur pada lokasi ke-4 dapat mencapai $>80^{\circ} \mathrm{C}$ di sumber (pusat). Pada mata air ke-5 lokasi sudah dialokasikan sebagai tempat pemandian air panas oleh penduduk lokal. Temperatur yang didapatkan tidak terlalu tinggi, sekitar $43^{\circ} \mathrm{C}$, dimana tergolong ke dalam air hangat.

Tabel 4. Data $\mathrm{pH}$ dan Temperatur Permukaan

\begin{tabular}{ccc}
\hline Sampel & $\mathbf{p H}$ & Temperatur permukaan $\left({ }^{\mathbf{0}} \mathbf{C}\right)$ \\
\hline 1 & 7,4 & 91 \\
2 & 6,8 & 80 \\
3 & 7,4 & 87 \\
4 & 7 & $49^{*}$ \\
5 & 6,7 & 43 \\
\hline diukur di pinggir telaga
\end{tabular}

Nilai pH mata air panas berkisar antara 6,8-7,4 (Tabel 4) sehingga dapat disimpulkan bahwa mata air panas Kecamatan Pauh Duo, Kabupaten Solok Selatan memiliki sistem panas bumi didominasi air. Hal ini juga sesuai dengan Wisnandary dan Alamsyah (2012) yang menyebutkan bahwa sistem panas bumi di daerah Muara Laboh didominasi oleh air. Mengacu pada hasil pengukuran $\mathrm{pH}$, jenis mata air panas bumi daerah penelitian diperkirakan adalah jenis air alkali klorida, karena air tipe ini memiliki pH sekitar 6-7.5 dan sistem reservoir dominasi air.

Konsentrasi silika yang tinggi menandakan temperatur reservoir panas bumi di daerah tersebut juga tinggi (Rimstidt, 1983). Pada daerah penelitian, mata air ke-1 memiliki manifestasi permukaan berupa sinter silika. Hal ini dibuktikan oleh penelitian Endhovani (2015). Dari hasil uji kandungan sampel didapatkan kandungan silika sebesar 89,33\%. Oleh karena itu, pada mata air ke-1 dilakukan penghitungan nilai resistivitas listrik sinter silika untuk melihat karakteristik hambatan jenis dari sinter silika (Tabel 5). Nilai resistivitas listrik sinter silika yang didapatkan berada dalam rentang nilai 30,41 - 34,19 $\Omega$ m. 
Tabel 5. Data Resistivitas Listrik Sinter Silika

\begin{tabular}{cc}
\hline Sampel & Resististivitas $(\mathbf{\Omega m})$ \\
\hline 1A & 30,41 \\
1B & 34,19 \\
1C & 30,41 \\
1D & 30,41 \\
1E & 30,41 \\
\hline Rata-rata & $\mathbf{3 1 , 1 6}$ \\
\hline
\end{tabular}

Nilai resistivitas air juga merupakan salah satu parameter untuk mengetahui mineral terlarut di dalam air. Berdasarkan uji konduktivitas air menggunakan conductivity meter didapatkan resistivitas air dengan menggunakan rumus $1 / \sigma$. Rentang nilai resistivitas air yang didapatkan 57,57-76,33 $\Omega \mathrm{m}$ dan konduktivitas air 0,0131-0,01737 S/m (Tabel 6). Nilai resistivitar air yang didapatkan berada pada kisaran nilai resistivitas air tanah (groundwater) 10$100 \Omega \mathrm{m}$. Hal ini mengindikasikan bahwa sumber mata air panas berasal dari air permukaan yang mengalami proses boiling dengan batuan panas yang mengalir melalui rekahan atau patahan.

Tabel 6. Data Resistivitas Air dan Konduktivitas Air

\begin{tabular}{ccc}
\hline Sampel & Konduktivitas (S/m) & Resistivitas $(\mathbf{\Omega m})$ \\
\hline 1 & 0,01737 & 57,57052 \\
2 & 0,01666 & 60,02400 \\
3 & 0,01310 & 76,33587 \\
4 & 0,01703 & 58,71990 \\
5 & 0,01675 & 59,70149 \\
\hline
\end{tabular}

\subsection{Estimasi Temperatur Reservoir}

Jika dilihat pada hasil uji kandungan air (Tabel 3), semua daerah penelitian mengandung konsentrasi $\mathrm{Ca}$ yang tinggi sehingga persamaan geotermomoter $\mathrm{Na}-\mathrm{K}$ kurang cocok digunakan untuk air pada daerah penelitian. Oleh karena itu, pada daerah penelitian hanya dapat digunakan geotermometer silika dan geotermometer Na-K-Ca.

\subsubsection{Geotermometer Na-K-Ca}

Hasil estimasi temperatur menggunakan persamaan geotermometer Na-K-Ca dapat dilihat pada Tabel 7. Nilai estimasi yang didapatkan berkisar $224,64{ }^{\circ} \mathrm{C}-248,07^{\circ} \mathrm{C}$

\subsubsection{Geotermometer $\mathrm{SiO}_{2}$}

Estimasi temperatur menggunakan 6 jenis persamaan geotermometer silika dapat dilihat pada Tabel 7. Mengacu kepada persamaan geotermometer Na-K-Ca, nilai estimasi temperatur reservoir panas bumi pada lima mata air panas yang mendekati adalah nilai yang didapat dari persamaan geotermometer silika amorf. Hasil estimasi temperatur reservoir menggunakan persamaan Na-K-Ca lebih rendah dari silika amorf, namun selisih temperatur kedua persamaan tersebut kecil $\left( \pm 50^{\circ} \mathrm{C}\right)$. Estimasi temperatur reservoir menggunakan persamaan geotermometer Na-K-Ca berkisar $224,64-248,07{ }^{\circ} \mathrm{C}$, sedangkan menggunakan persamaan geotermometer silika amorf $267,13-331,96{ }^{\circ} \mathrm{C}$. 
Tabel 7. Hasil estimasi temperatur reservoir panas bumi menggunakan persamaan geotermometer silika dan $\mathrm{Na}-\mathrm{K}-\mathrm{Ca}$

\begin{tabular}{|c|c|c|c|c|c|c|}
\hline \multirow{2}{*}{ Geotermometer } & \multirow{2}{*}{ Persamaan } & \multicolumn{5}{|c|}{ Estimasi Temperatur Setiap Sampel $\left({ }^{\circ} \mathrm{C}\right)$} \\
\hline & & 1 & 2 & 3 & 4 & 5 \\
\hline \multirow{7}{*}{$\begin{array}{l}\text { Geotermometer } \\
\text { silika }\end{array}$} & $\begin{array}{l}\text { Quartz-no steam loss } \\
\text { (Fournier, 1979) } \\
\text { Quartz maximum } \\
\text { (Fournier, 1979) }\end{array}$ & 316,09 & $\begin{array}{l}392,49 \\
329,26\end{array}$ & 423,85 & 306,90 & 380,63 \\
\hline & $\begin{array}{l}\text { Chalcedony } \\
\text { (Arnarsson) } \\
\text { Quartz }\end{array}$ & 364,83 & 386,20 & 422,70 & 350,21 & 372,53 \\
\hline & (Arnarsson) & 434,70 & 453,78 & 495,73 & 423,02 & 441,25 \\
\hline & $\begin{array}{l}\text { Chalcedony } \\
\text { (Fournier, 1979) }\end{array}$ & 404,46 & 430,56 & 475,74 & 386,75 & 413,84 \\
\hline & $\begin{array}{l}\text { Amorphous silica } \\
\text { (Fournier, 1979) }\end{array}$ & 267,13 & 290,67 & 331,96 & 251,28 & 275,56 \\
\hline & (Fournier, 1979) & 921,81 & 1228,79 & 2077,39 & 769,48 & 1019,62 \\
\hline & (Fournier, 1979) & 346,82 & 369,31 & 408,03 & 331,49 & 354,91 \\
\hline \multicolumn{7}{|l|}{ Geotermometer } \\
\hline $\mathrm{Na}-\mathrm{K}-\mathrm{Ca}$ & $\mathrm{Na}-\mathrm{K}-\mathrm{Ca}$ & 229,23 & 233,42 & 248,07 & 230,40 & 224,64 \\
\hline
\end{tabular}

Menurut Saptadji (2009), konsentrasi silika dikontrol oleh kelarutan berbagai mineral silikat dalam batuan. Geotermometer kuarsa umumnya baik digunakan untuk reservoir bertemperatur $>150^{\circ} \mathrm{C}$. Di bawah $150^{\circ} \mathrm{C}$ kandungan silika dikontrol oleh kalsedon. Pada fluida reservoir bersuhu $>220^{\circ} \mathrm{C}$ kuarsa dapat mengendap akibat pendinginan perlahan, apabila pendinginan berlangsung dengan sangat cepat, maka yang terbentuk/mengendap adalah silika amorf. Hal ini diperkuat dengan penelitian Susilo (2016) yang mendapatkan struktur sinter silika di daerah mata air panas Sapan Maluluang memiliki fasa amorf. Hal ini mendukung temuan dalam penelitian ini dimana persamaan geotermometer silika yang sesuai pada daerah penelitian adalah persamaan geotermometer silika amorf (amorphous silica).

Hasil estimasi temperatur antara kelima sampel mata air panas relatif sama. Hal ini mengindikasikan bahwa lima mata air panas di daerah penelitian berada pada satu reservoir yang sama. Hal ini diperkuat dengan hasil analisis kandungan kimia (Tabel 3), pH, dan temperatur permukaan (Tabel 4) yang menyebutkan daerah penelitian memiliki sistem dan jenis fluida yang sama.

\section{KESIMPULAN}

Berdasarkan hasil pengujian, perhitungan dan analisis data yang telah dilakukan pada 5 mata air panas di Kecamatan Pauh Duo, Kabupaten Solok Selatan didapatkan persamaan geotermometer yang cocok pada daerah penelitian adalah persamaan geotermometer $\mathrm{Na}-\mathrm{K}-\mathrm{Ca}$ dan silika amorf dengan nilai estimasi temperatur reservoir $224^{\circ} \mathrm{C}-332^{\circ} \mathrm{C}$ dan diperkirakan lokasi daerah penelitian memiliki satu kesatuan reservoir. Nilai estimasi ini berada dalam kisaran nilai estimasi temperatur reservoir yang diperoleh oleh PT. Supreme Energy yaitu $210^{\circ} \mathrm{C}-320^{\circ} \mathrm{C}$. Mata air panas di daerah penelitian memiliki $\mathrm{pH}$ netral dengan nilai berkisar dari 6,8 sampai 7,4. Berdasarkan nilai ini, tipe fluida mata air panas di Kecamatan Pauh Duo, Kabupaten Solok Selatan adalah alkali klorida dan sistem panas buminya didominasi oleh air.

\section{DAFTAR PUSTAKA}

Aribowo, Y., 2011, Prediksi Temperatur Reservoir Panasbumi dengan Menggunakan Metoda Geotermometer Kimia Fluida, Vol. 32, No.3, Teknik, 234-238

Arnason, 2000, The Resistivity Structure of High Temperature Geothermal Systems in Iceland, Proceedings World Geothermal Congress 2000, hal 923-928 
Endhovani, R., dan Putra, A., 2015, Analisis Konduktivitas Termal dan Porositas Sinter Silika Sumber Mata Air Panas di Sapan Maluluang, Kecamatan Alam Pauh Duo, Kabupaten Solok Selatan, Jurnal Fisika Unand, Padang.

Karingithi C.W, 2009, Chemical geothermometers for Geothermal Exploration, United Nations University, hal. 1-12

Munandar, A., Suhanto, E., Kusnadi, D., Idral, A., Solviah, M., 2003, Penyelidikan Terpadu Daerah Panas Bumi Gunung Talang Kabupaten Solok - Sumatera Barat, Kolakium Hasil Kegiatan Inventarisasi Sumber Daya Mineral - DIM, SUBDIT Panas Bumi.

Nugroho, B.E. dan Putra, A., 2015, Estimasi Temperatur Reservoir Panas Bumi Berdasarkan Resistivitas Listrik Teras Silika Di Sekitar Mata Air Panas Kecamatan Alam Pauh Duo, Kabupaten Solok Selatan, Jurnal Fisika Unand, Vol.4, No.4, Jur.Fisika Unand.

Rimstidt, 1983, Geothermal Mineralization I: The Mechanism of Formation of The Beowawe, Nevada Siliceous Sinter Deposit, American Journal of Science, 861-875

Saptadji, N.M., 2009, Teknik Panas Bumi, Departemen Teknik Perminyakan Fakultas Ilmu Kebumian dan Teknologi Mineral Institut Teknologi Bandung, Bandung.

Susilo, H., 2016, Pengaruh Konsentrasi Naoh Pada Sintesis Nanosilika Dari Sinter Silika Mata Air Panas Sentral, Solok Selatan, Sumatera Barat Dengan Metode Kopresipitasi, Skripsi. FMIPA, Unand, Padang.

Wisnandary dan Alamsyah, 2012, Zero Generation of Muara Laboh Numerical Model: Role of Heat Loss, Vol.36, GRC Transactions, hal 825-830

Yock, A., 2009, Geotermometry, Presented at Short Course on Surface Exploration for Geothermal Resources in Ahuachapan and Santa Tecla, El Salvador, 17-30 October, 2009 